\title{
The circadian clock protein Period 1 regulates expression of the renal epithelial sodium channel in mice
}

\author{
Michelle L. Gumz,1,2 Lisa R. Stow, ${ }^{1,3}$ I. Jeanette Lynch,1,2 Megan M. Greenlee,1,3 Alicia Rudin,,1,2 \\ Brian D. Cain, ${ }^{4}$ David R. Weaver, ${ }^{5}$ and Charles S. Wingo ${ }^{1,2,3}$ \\ 1VA Medical Center, Gainesville, Florida, USA. ${ }^{2}$ Department of Medicine, Division of Nephrology, ${ }^{3}$ Department of Physiology and Functional Genomics, and \\ ${ }^{4}$ Department of Biochemistry and Molecular Biology, University of Florida, Gainesville, Florida, USA. 5Department of Neurobiology, \\ University of Massachusetts Medical School, Worcester, Massachusetts, USA.
}

\begin{abstract}
The mineralocorticoid aldosterone is a major regulator of sodium transport in target epithelia and contributes to the control of blood pressure and cardiac function. It specifically functions to increase renal absorption of sodium from tubular fluid via regulation of the $\alpha$ subunit of the epithelial sodium channel $(\alpha \mathrm{ENaC})$. We previously used microarray technology to identify the immediate transcriptional targets of aldosterone in a mouse inner medullary collecting duct cell line and found that the transcript induced to the greatest extent was the circadian clock gene Period 1 . Here, we investigated the role of Period 1 in mediating the downstream effects of aldosterone in renal cells. Aldosterone treatment stimulated expression of Period 1 (Per1) mRNA in renal collecting duct cell lines and in the rodent kidney. RNA silencing of Period 1 dramatically decreased expression of $\mathrm{mRNA}$ encoding $\alpha \mathrm{ENaC}$ in the presence or absence of aldosterone. Furthermore, expression of $\alpha E N a C$-encoding mRNA was attenuated in the renal medulla of mice with disruption of the Per1 gene, and these mice exhibited increased urinary sodium excretion. Renal $\alpha E N a C$-encoding $m R N A$ was expressed in an apparent circadian pattern, and this pattern was dramatically altered in mice lacking functional Period genes. These results suggest a role for Period 1 in the regulation of the renal epithelial sodium channel and more broadly implicate the circadian clock in control of sodium balance.
\end{abstract}

\section{Introduction}

Sodium $(\mathrm{Na})$ is the principal extracellular cation and plays a vital role in maintaining extracellular fluid volume and therefore blood pressure. The mineralocorticoid hormone aldosterone acts directly on the distal nephron and collecting duct to increase Na reabsorption, which in turn increases blood volume, vascular reactivity, and blood pressure $(1,2)$. Indeed, most known forms of monogenic hypertension are the result of a defect in the downstream signaling targets of aldosterone (3). In target epithelia, aldosterone increases the absorption of $\mathrm{Na}$ from the tubular fluid into the extracellular space by increasing the number and activity of epithelial sodium channels (ENaCs) at the apical membrane and the $\mathrm{Na}^{+} / \mathrm{K}^{+}$-ATPase at the basolateral membrane. Transepithelial $\mathrm{Na}$ and $\mathrm{H}_{2} \mathrm{O}$ reabsorption increases blood volume and vascular reactivity and consequently systemic blood pressure. Whereas these late effects of aldosterone action have been well characterized, the mediators of this action have not.

We have shown that SV40-transformed mouse inner medullary collecting duct (mIMCD-3) cells, derived from the terminal third of the inner medullary collecting duct (IMCD), represent a model for aldosterone action (4). These cells express $11 \beta$-hydroxy-steroid

Conflict of interest: The authors have declared that no conflict of interest exists. Nonstandard abbreviations used: bHLH, basic helix-loop-helix; CCD, cortical collecting duct; CT, circadian time; ENaC, epithelial sodium channel; GR, glucocorticoid receptor; hnRNA, heterogeneous nuclear RNA; IMCD, inner medullary collecting duct; MR, mineralocorticoid receptor; OMCD, outer medullary collecting duct; Per1, Period 1; QPCR, quantitative real-time RT-PCR; RAAS, renin angiotensin aldosterone system; Sgk1, serum- and glucocorticoid-regulated kinase 1; TKO, Period 1, 2, 3 (triple) knockout.

Citation for this article: J. Clin. Invest. 119:2423-2434 (2009). doi:10.1172/JCI36908. dehydrogenase type 2 , which confers mineralocorticoid specificity; $\alpha \mathrm{ENaC}$, the regulated and rate-limiting subunit of renal ENaC function $(5,6)$; and the mineralocorticoid receptor (MR). These transcripts are markers of aldosterone-responsive cells. In order to identify the acute transcriptional effects of aldosterone, we previously used a microarray analysis to evaluate changes in gene expression in mIMCD-3 cells after an acute exposure to aldosterone (4). The most highly induced transcript in the study was Period 1 (Per1), previously described as period homolog. The Per1 gene encodes a member of the basic helix-loop-helix-PeriodArnt-SIM (bHLH-PAS) domain-containing family of transcription factors that recognize E-box motifs in the promoters of target genes. Per 1 is an important component of the circadian clock; its discovery and characterization provided essential insight into the mechanism behind regulation of circadian patterns (7). Many physiological processes are governed by or exhibit a circadian pattern, including the sleep-wake cycle, heartbeat, body temperature, hormone secretion, renal blood flow, and renal electrolyte excretion $(8,9)$. The circadian clock pacemaker is the suprachiasmatic nucleus (SCN), located in the ventral hypothalamus. The SCN processes information from "peripheral clocks," including the liver and kidney. Positive and negative regulatory feedback loops make up the central circadian clock. In the positive loop, $2 \mathrm{bHLH}$ transcription factors, Clock and Bmal1, heterodimerize to drive transcription of Per1, Per2, and cryptochrome (Cry). In the negative loop, Cry/Per oligomers shuttle between the cytoplasm and nucleus to inhibit Clock/Bmal1, thereby decreasing their own transcription. Transcript and protein levels of these circadian transcription factors rise and fall over the course of an approximately 24-hour period. 


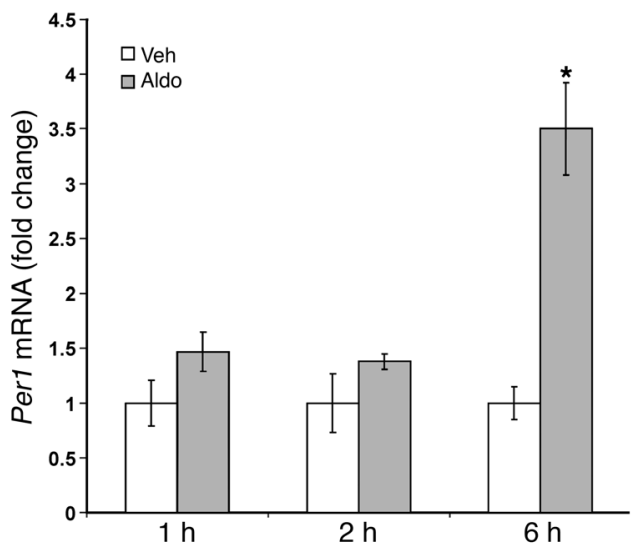

Figure 1

Per1 is induced by aldosterone in vivo. Male Sprague-Dawley rats were injected with vehicle (ethanol, Veh) or aldosterone $(1 \mathrm{mg} / \mathrm{kg}$, Aldo). Animals were euthanized and inner medullas dissected 1, 2, or 6 hours after the injection. QPCR was used to measure changes in gene expression. Fold change values were calculated relative to actin and compared with vehicle-treated control animals. Data are presented as mean $\pm \mathrm{SEM} ; n \geq 5 .{ }^{*} P<0.05$ versus vehicle.

Diurnal fluctuations in blood pressure and urinary volume excretion were first reported more than 100 years ago, by Zadek in 1881 and Vogel in 1854, respectively (reviewed in ref. 10). A diurnal rhythm of urinary sodium, potassium, and chloride excretion has been established for many decades (11-13). In normal individuals, electrolyte excretion and urine production are greater during the day than at night. Alteration of this circadian pattern is often associated with pathophysiological conditions, including hypertension and cardiovascular disease $(14,15)$. Whereas these clinical observations are well established, the underlying molecular mechanisms for the circadian fluctuation in electrolyte excretion and blood pressure are not understood.

Here, we report upregulation of Per1 by aldosterone and further confirm the upregulation of Per1 in the kidney in vivo. To characterize the aldosterone-mediated regulation of Per1, we cloned and characterized the Per 1 promoter and used RNA interference to analyze the role of the MR and the glucocorticoid receptor (GR) in the regulation of Per1 by aldosterone. In turn, RNA interference was used to evaluate the effect of Per1 knockdown on aldosterone action. Per1 knockdown prevented the induction of $\alpha \mathrm{ENaC}$ by aldosterone. Interestingly, knockdown of Per1 in the absence of aldosterone also led to a decrease in $\alpha \mathrm{ENaC}$ levels, which suggests that Per 1 contributes to the basal regulation of this subunit. Furthermore, $\alpha E N a C$ was downregulated in the inner and outer medulla in vivo in Per1-deficient

\section{Figure 2}

Per1 is upregulated by aldosterone in mIMCD-3 cells. (A) QPCR was used to calculate changes in gene expression of Per1, Per2, Sgk1, and $\alpha \mathrm{ENaC}$ in aldosterone-treated compared with vehicle-treated cells. Fold change values were normalized against actin levels, relative to the vehicle control, and are presented as mean $\pm \mathrm{SD} ; n=3$. ${ }^{*} P<0.05$ versus vehicle control. (B) Total cell lysate was collected from mIMCD-3 cells treated with vehicle or aldosterone for 6 hours. Western blot analysis was performed using an anti-Per1 antibody. GAPDH was used as a loading control. compared with wild-type mice. Finally, we show for the first time to our knowledge that $\alpha \mathrm{ENaC}$ mRNA is expressed in a circadian pattern similar to Per1 and that this expression profile is altered in mice lacking functional Period genes. These data clearly demonstrate the importance of the circadian rhythm gene Per1 in the regulation of $\alpha \mathrm{ENaC}$ expression. Such findings provide the first evidence of a direct molecular link between the circadian clock and a mediator of $\mathrm{Na}$ balance.

\section{Results}

Per1 is induced by aldosterone in vivo. In order to evaluate the in vivo regulation of Per1, we injected rats with vehicle (ethanol) or aldosterone. Animals were euthanized, and the inner medulla was dissected at intervals up to 6 hours following the injection of hormone or vehicle. Aldosterone-induced changes in Per 1 mRNA levels were determined relative to vehicle-treated control animals. Per1 expression increased more than 3-fold in animals exposed to aldosterone for 6 hours (Figure 1). This result suggests that Per 1 is subject to aldosterone regulation in vivo.

Circadian rhythm genes are upregulated by aldosterone. Aldosterone induced 2 circadian rhythm genes in our earlier microarray studies: period homolog 1 (Per1) and period homolog 2 (Per2) (4). Per1 was upregulated to a greater extent than any other gene in the microarray study. To extend the study of the regulation of Per1 by aldosterone and to consider the effect of aldosterone on Per2, we treated mIMCD-3 cells with vehicle (ethanol) or $1 \mu \mathrm{M}$ aldosterone for 1 or 24 hours (Figure 2A). As a control for the efficacy of aldosterone treatment, expression of serum- and glucocorticoidregulated kinase 1 (Sgk1) was measured. $\mathrm{Sgk} 1$ is a well characterized aldosterone target and regulator of $\mathrm{ENaC}(16)$. As expected, Per 1 and Sgk1 mRNA levels increased more than 4-fold and 2-fold, respectively, after 1 hour of hormone treatment. These results were entirely consistent with our previous report (4). Interestingly, Per2 was not noticeably upregulated at 1 hour, even though the results of our microarray indicated a nearly 2 -fold increase in Per2 at that time point. However, Per 2 expression increased more than 2 -fold after 24 hours of aldosterone treatment. Thus, we focused our attention on the more highly regulated transcript, Per1.
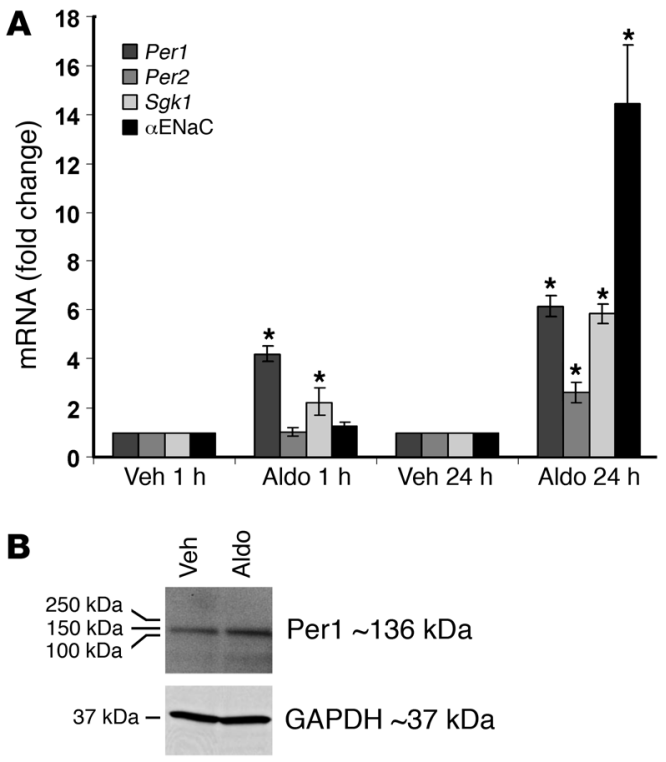


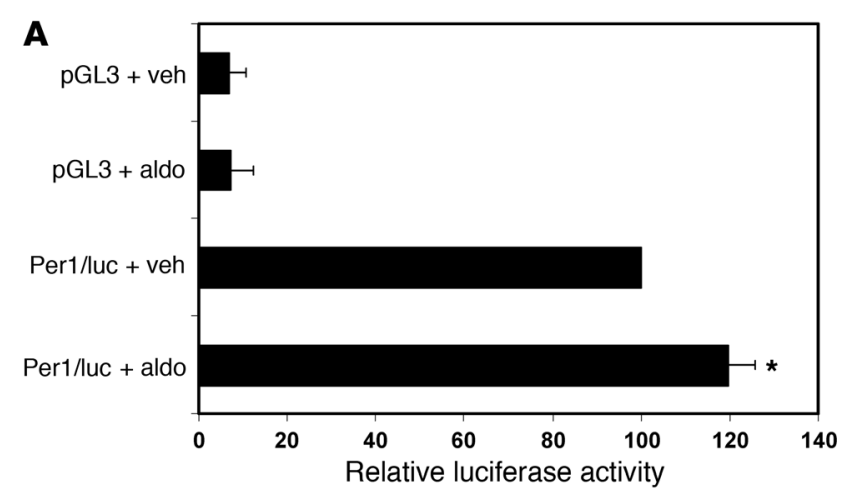

B

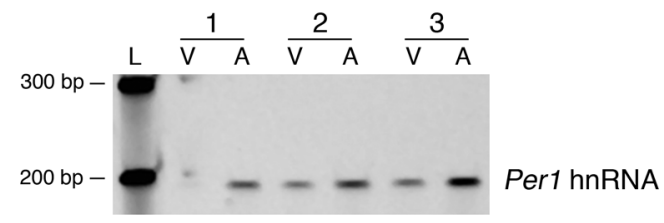

C

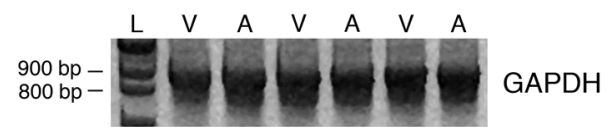

To address the issue of the concentration of aldosterone used in these experiments, we preformed a dose-response study in mIMCD-3 cells (data not shown). Per1 was significantly increased by aldosterone at $0.1 \mu \mathrm{M}(2.8 \pm 0.06$-fold increase, $n=3, P<0.001)$ and at $0.01 \mu \mathrm{M}(1.24 \pm 0.04$-fold increase, $n=3, P<0.001)$. These results indicate that the induction of Per1 by aldosterone occurs at sub-micromolar doses of the hormone.

The transcriptional upregulation of the Scnn1a gene (hereafter referred to as $\alpha \mathrm{ENaC}$ ) by aldosterone is a well-documented effect $(17,18)$, but the effect of aldosterone on $\alpha \mathrm{ENaC}$ mRNA levels had not been studied in mIMCD- 3 cells. $\alpha \mathrm{ENaC}$ mRNA levels were unchanged after 1 hour of aldosterone treatment (Figure 2A). This was expected, because the known transcriptional effects of aldosterone on $\alpha \mathrm{ENaC}$ occur only after several hours of hormone exposure (17). However, after 24 hours of aldosterone treatment in mIMCD- 3 cells, $\alpha$ ENaC expression increased by nearly 15 -fold. The results validated mIMCD-3 cells as an appropriate in vitro model for investigation of aldosterone action on $\alpha \mathrm{ENaC}$ gene expression. To confirm that aldosterone increased Per1 protein levels, we performed Western blot analysis on total cell lysates from mIMCD-3 cells treated with vehicle or aldosterone for 6 hours (Figure 2B). Per1 protein levels increased after aldosterone treatment.

Aldosterone stimulates Per 1 transcription. Two approaches were taken to determine whether aldosterone action on Per1 was a direct result of transcriptional activation of the Per1 gene. A BAC clone containing part of mouse chromosome 11 was used as template for a PCR-based approach to clone the Per1 promoter (data not shown). A 2,002-bp fragment of the Per1 promoter, up to but not including the translation start site, was cloned in-frame with the luciferase cDNA to generate the plasmid Per1/luc. mIMCD-3 cells were transfected with pGL3 or Per $1 /$ luc for 24 hours and then treated with vehicle (ethanol) or $1 \mu \mathrm{M}$ aldosterone for 6 hours. Aldosterone treatment had no effect on the negative control pGL3 but increased Per1/luc luciferase activity by only $20 \%$ (Figure 3A) $(P<0.05)$. Although this difference was statistically significant, the

\section{Figure 3}

Per1 is transcriptionally regulated by aldosterone. (A) Mouse IMCD-3 cells were transfected with $\mathrm{pRL}$ Renilla luciferase and either the $\mathrm{pGL} 3$ empty vector or a plasmid containing 2,002 bp of the Per1 promoter cloned in front of the firefly luciferase cDNA (Per1/luc). Twenty-four hours later, cells were treated with vehicle or aldosterone for 6 hours. Data are presented as mean $\pm \mathrm{SEM} ; n=4$. ${ }^{\star} P<0.05$ versus Per/luc plus vehicle. (B) Primers were designed to amplify a 191-bp region of the Per1 gene between exon 7 and intron 7 in order to measure hnRNA as an indicator of transcriptional activity in 3 (nos. 1-3) independent sets of template from vehicle- or aldosterone-treated mIMCD-3 cells; $n=3$. L, ladder; V, vehicle; A, aldosterone. (C) An 874-bp GAPDH product was amplified as a PCR control.

magnitude of increase was less than what was observed by using quantitative real-time RT-PCR (QPCR) to measure steady-state Per1 mRNA levels in the presence of aldosterone in mIMCD-3 cells. Compared with a PGL3 control vector containing the SV40 promoter, the level of luciferase activity of Per1/luc was 2- to 3 -fold higher (data not shown). This high background may have obscured the effect of external stimulation on the Per1 luciferase construct. Therefore, we tested direct transcriptional activity from the endogenous Per1 gene.

Analysis of the short-lived heterogeneous nuclear RNA (hnRNA) is a direct measure of transcriptional activity (19). Primers were designed to amplify a region of the Per 1 gene spanning the boundary between exon 7 and intron 7 . Three independent sets of cDNA from vehicle- or aldosterone-treated cells were used as template for hnRNA RT-PCR reactions (Figure 3B). As a control for the amount of cDNA used in the hnRNA PCR reactions, primers were used to amplify a fragment of the GAPDH cDNA (Figure 3C). GAPDH levels were equivalent in all samples, regardless of aldosterone treatment. In 3 independent samples, Per1 hnRNA levels were consistently higher in aldosterone-treated samples compared with the vehicle-treated control, demonstrating that aldosterone induces Per1 transcription.

$M R$ and GR mediate aldosterone-induced Per1 expression. Using pharmacological inhibitors, we previously showed that MR and GR both contributed to the induction of early aldosterone targets (4). This was consistent with the known contribution of each receptor to aldosterone action (20). To demonstrate hormone receptor-mediated regulation of the Per1 gene, we used an RNA silencing (siRNA) approach to knock down expression of MR, GR, or both receptors. Subsequent changes in Per1 expression following aldosterone treatment of mIMCD-3 cells were measured. Each of 4 independent MR-specific or GR-specific siRNAs was tested in

\section{Table 1}

Effect of MR or GR siRNA on hormone receptor mRNA levels

\begin{tabular}{lccc}
\multicolumn{2}{c}{ MR (Nr3c2) } & \multicolumn{2}{c}{ GR (Nr3c1) } \\
siRNA $^{A}$ & $\begin{array}{c}\text { \% Decrease } \\
\text { in mRNAB }\end{array}$ & siRNA $^{\text {A }}$ & $\begin{array}{c}\% \text { Decrease } \\
\text { in mRNA }\end{array}$ \\
MR9 & $43 \pm 3$ & GR9 & $75 \pm 1$ \\
MR10 & $89 \pm 3$ & GR10 & $87 \pm 1$ \\
MR11 & $80 \pm 3$ & GR11 & $43 \pm 1$ \\
MR12 & $65 \pm 5$ & GR12 & $79 \pm 2$ \\
\hline
\end{tabular}

APurchased from Dharmacon. BRelative to non-target siRNA-transfected cells. Data are presented as mean \pm SEM. 


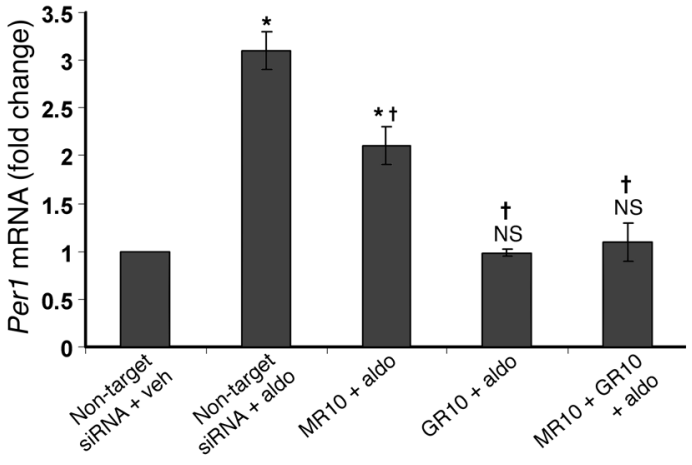

mIMCD-3 cells (Table 1). Transfection with MR10 siRNA yielded the best knockdown in MR mRNA levels, a nearly 90\% reduction. Transfection with GR-10 siRNA yielded a comparable knockdown in GR mRNA levels.

MR10 or GR10 siRNA was transfected into mIMCD-3 cells 24 hours prior to 1 -hour treatment with vehicle or aldosterone in order to determine the effect of receptor knockdown on Per1 expression (Figure 4). MR knockdown inhibited the response of Per1 to aldosterone by approximately $30 \%$, while GR knockdown essentially prevented hormonal induction of Per1. These results are consistent with our previous report using spironolactone and mifepristone, pharmacological inhibitors of MR and GR, respectively (4). These data indicate that both MR and GR contribute to aldosterone action in mIMCD-3 cells.

Per1 knockdown prevents the aldosterone-mediated induction of $\alpha E N a C$ expression. $\mathrm{ENaC}$ is a heteromeric channel, thought to consist of equal numbers of $\alpha, \beta$, and $\gamma$ subunits (21). In the kidney, $\alpha \mathrm{ENaC}$ is the aldosterone-responsive subunit and acts as the rate-limiting component for channel formation $(5,22)$. To test the hypothesis that Per1 mediates the downstream action of aldosterone, we determined the effect of Per1 knockdown on the aldosterone-mediated induction of $\alpha \mathrm{ENaC}$ (Figure 5). mIMCD-3 cells were transfected with a non-target siRNA or each of 4 independent Per1-specific siRNAs. Twenty-four hours later, cells were treated with vehicle or aldosterone for an additional 24 hours. Fold changes in mRNA levels were calculated relative to the non-target siRNA-transfected cells treated with vehicle. Importantly, Per1 was induced by aldosterone in the non-target siRNA-transfected cells, demonstrating that siRNA transfection did not negatively affect hormone responsiveness. However, the presence of Per1-specific siRNA effectively prevented the aldosterone-mediated induction of Per1 (Figure 5A). Transfection with each of the 4 independent Per1 siRNAs resulted in effective knockdown of Per1 expression. Indeed, expres-

\section{Figure 5}

Per1 knockdown attenuates the response of $\alpha \mathrm{ENaC}$ to aldosterone. Mouse IMCD-3 cells were transfected with Per1 siRNA sequences 24 hours prior to vehicle or aldosterone treatment. QPCR was used to analyze changes in gene expression of Per1 (A), Sgk1 (B), and $\alpha \mathrm{ENaC}(\mathbf{C})$ after Per1 knockdown in the presence of aldosterone compared with vehicle-treated non-target siRNA-transfected cells. Fold change values were normalized against actin and are presented as mean \pm SEM; $n=4$ ( $n=3$ for Per1-5 and Per1-6). ${ }^{*} P<0.05$ versus non-target siRNA vehicle control; NS, not significant versus non-target siRNA-transfected cells treated with vehicle; łnot significant versus non-target siRNA aldosterone-treated sample.

\section{Figure 4}

Contribution of MR and GR to the aldosterone-mediated regulation of Per1. Mouse IMCD-3 cells were transfected with a non-target control siRNA or siRNA for MR (MR10) or GR (GR10). Twenty-four hours later, cells were treated with vehicle or aldosterone for 1 hour. Changes in gene expression were measured using QPCR. Data are presented as mean $\pm \mathrm{SEM} ; n=3$. ${ }^{*} P<0.05$ versus non-target siRNA-transfected cells treated with vehicle; ${ }^{\dagger} P<0.05$ versus non-target siRNA-transfected cells treated with aldosterone; NS, not significant versus nontarget siRNA-transfected cells treated with vehicle. sion levels of Per1 in Per1 siRNA-transfected, aldosterone-treated cells were not significantly different from those in the non-target siRNA-transfected, vehicle-treated control.

Next, the effect of Per1 knockdown on Sgk1 was evaluated (Figure $5 \mathrm{~B}$ ). As was observed with Per1, transfection with the non-target siRNA did not affect the induction of Sgk1 by aldosterone. Interestingly, the level of Sgk1 expression in aldosterone-treated
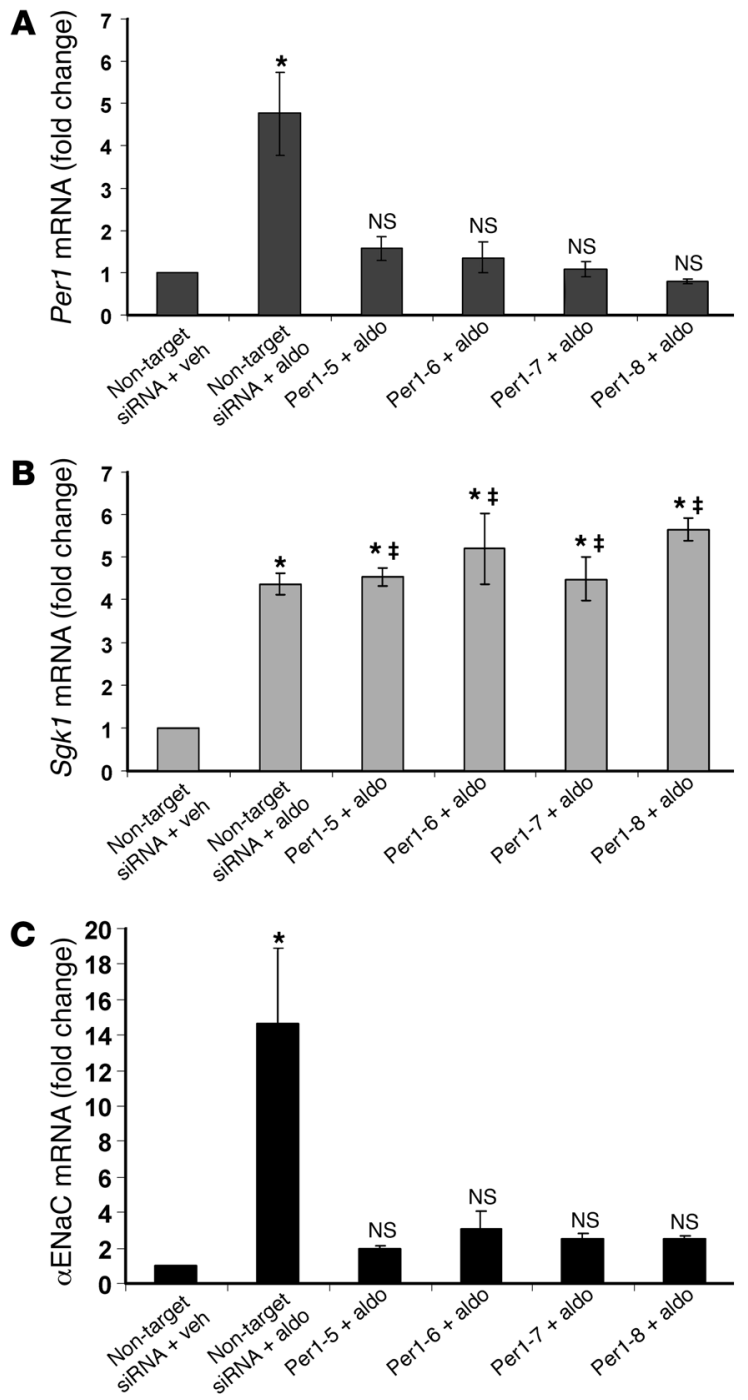


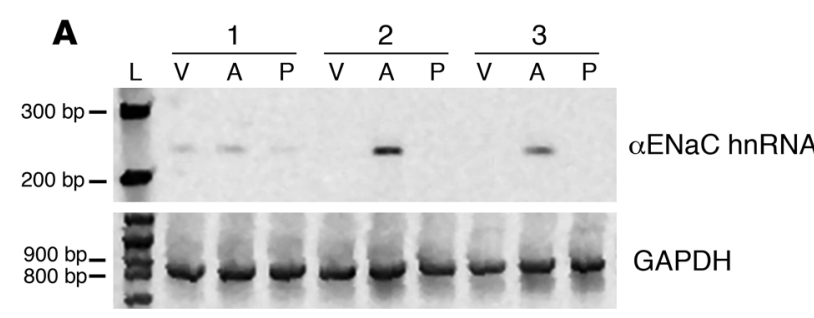

B

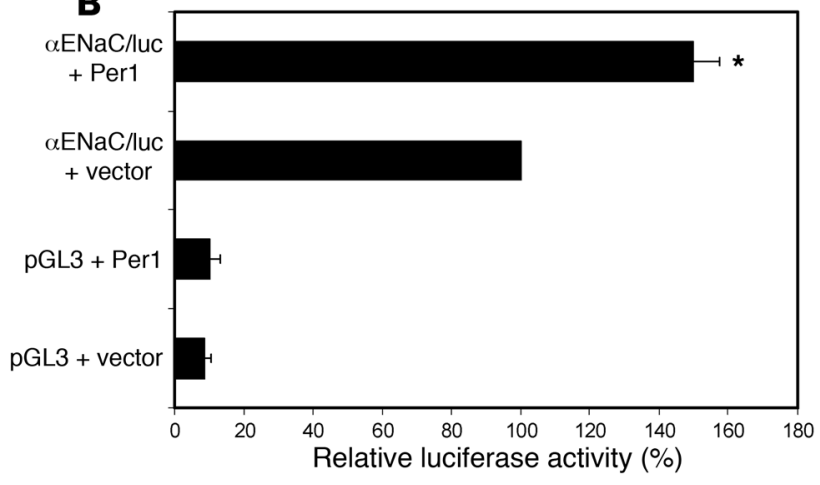

mIMCD-3 cells was equivalent in non-target siRNA-transfected cells and Per1 siRNA-transfected cells, indicating that knockdown of Per1 had no effect on the aldosterone-mediated increase in Sgk1 mRNA expression. This result was consistent with each of the 4 independent Per1-specific siRNAs.

As was observed previously (see Figure 2A), the increase in $\alpha \mathrm{ENaC}$ mRNA levels in response to 24 hours of aldosterone treatment was nearly 15 -fold (Figure 5C). Transfection with a non-targeting siRNA control did not interfere with the response of $\alpha E N a C$ to aldosterone. Per 1 knockdown resulted in a dramatic reduction in $\alpha \mathrm{ENaC}$ mRNA levels. Indeed, levels of $\alpha \mathrm{ENaC}$ in Per1 siRNA-transfected cells were not statistically different from those in the non-target siRNA-transfected, vehicle-treated control cells. Each of the Per1-specific siRNAs had an equivalent effect: knockdown of Per1 effectively prevented the induction of $\alpha \mathrm{ENaC}$ by aldosterone.

Effect of Per1 on aENaC occurs at the level of transcription. In order to determine the mechanism of the effect of Per1 knockdown on $\alpha \mathrm{ENaC}$ expression, we examined $\alpha \mathrm{ENaC}$ hnRNA levels (Figure $6 \mathrm{~A}$ ). Three independent sets of vehicle- or aldosterone-treated samples from mIMCD-3 cells transfected with a non-target siRNA or the most effective (see Figure 5A) Per-specific siRNA, Per1-8 siRNA, were used as template. Primers were designed to cross the boundary between exon 8 and intron 8 in the Scnn $1 a(\alpha E N a C)$ gene. Higher levels of $\alpha \mathrm{ENaC}$ hnRNA were detected in non-target siRNA-transfected cells treated with aldosterone compared with non-target siRNA-transfected cells treated with vehicle (top panel). In the presence of Per1-8 siRNA, levels of $\alpha E N a C$ hnRNA were virtually undetectable. These data indicate that the regulation of $\alpha \mathrm{ENaC}$ expression involving Per1 occurred at the level of transcription.

To further test the hypothesis that $\alpha \mathrm{ENaC}$ transcription is regulated by Per1, we assessed the effect of Per1 overexpression on $\alpha \mathrm{ENaC}$ promoter luciferase activity. mIMCD-3 cells were transfected with a control luciferase vector lacking promoter elements (pGL3) or the $\alpha \mathrm{ENaC}$ luciferase construct containing $1.3 \mathrm{kbp}$ of the mouse $\alpha E N a C$ promoter (23). Cells were cotransfected with either empty expression vector (pCMV-Sport6) or a Per1 expres-

\section{Figure 6}

Effect of Per1 knockdown on $\alpha \mathrm{ENaC}$ is transcriptional. (A) Top panel: Primers were designed to amplify a 238-bp region of the Scnn1a $(\alpha \mathrm{ENaC})$ gene between exon 8 and intron 8 in order to measure hnRNA as an indicator of transcriptional activity. Templates from 3 (nos. 1-3) independent sets of non-target siRNA- or Per1-8 siRNAtransfected mIMCD-3 cells treated with vehicle or aldosterone were used in PCR reactions; $n=3$. V, non-target siRNA-transfected cells plus vehicle; $A$, non-target siRNA-transfected cells plus aldosterone; P, Per1-8 plus aldosterone. Bottom panel: An 874-bp GAPDH product was amplified as a PCR control. (B) $\alpha E N a C$ promoter luciferase activity was measured as described in Figure 3. Mouse IMCD-3 cells were cotransfected with pGL3 or $\alpha \mathrm{ENaC/luc}$ and empty pCMVSport 6 vector or Per1 expression vector. Data are presented as mean \pm SEM; $n=4$. ${ }^{\star} P<0.05$ versus $\alpha \mathrm{ENaC} / \mathrm{luc}$ plus vector. sion plasmid (24). The results in Figure 6B demonstrate that overexpression of Per 1 led to a $50 \%$ increase in $\alpha \mathrm{ENaC}$ luciferase activity. Together, these data indicate that Per1 positively regulates $\alpha \mathrm{ENaC}$ transcription.

Since Per1 is known to function as a negative regulator of transcription in the circadian clock, we hypothesized that it could be acting on $\alpha \mathrm{ENaC}$ indirectly by inhibiting a repressor of $\alpha \mathrm{ENaC}$ transcription. The histone methyltransferases Dot 1 and AF9 have been identified as transcriptional repressors of $\alpha \operatorname{ENaC}(25,26)$. If Per 1 acts on $\alpha \mathrm{ENaC}$ via transcriptional inhibition of AF9 or Dot 1 , then knockdown of Per1 should result in increased expression of AF9 or Dot1. Levels of Dot1 and AF9 were measured in mIMCD-3 cells transfected with Per1-8 compared with non-target siRNA in the presence or absence of aldosterone. Knockdown of Per1 did not appear to have an effect on expression of either Dot 1 or AF9 (data not shown). The time course of Per1 knockdown indicated that the effect of Per1 knockdown on $\alpha E N a C$ expression occurred as early as 2 hours after aldosterone treatment. In vitro and in vivo results also suggested that Per1 contributed to the basal transcriptional regulation of $\alpha \mathrm{ENaC}$. To further investigate the possibility that Per1 directly regulates $\alpha \mathrm{ENaC}$, we analyzed the Scnn1a promoter for possible Per1 response elements. The bHLH transcription factors of the circadian clock modulate transcription via binding of $\mathrm{E}$ box motifs in the promoters of target genes. The murine $\alpha \mathrm{ENaC}$ promoter was analyzed, and, in support of the hypothesis that Per 1 may regulate $\alpha \mathrm{ENaC}$ directly, at least 4 putative $\mathrm{E}$ box motifs were observed, at positions $-1,825,-1,795,-698$, and -681 relative to the transcription start site. Given these results, it is possible that Per 1 acts directly on $\alpha \mathrm{ENaC}$.

Aldosterone targets are induced in mIMCD-K2 cells. To determine whether our findings in mIMCD-3 cells could be demonstrated in a separate IMCD cell line, we studied the effect of aldosterone on Per1, Per2, and $\alpha \mathrm{ENaC}$ in mIMCD-K2 cells (Supplemental Figure 1; supplemental material available online with this article; doi:10.1172/ JCI36908DS1). mIMCD-K2 cells are an immortalized renal epithelial cell line derived from the initial segment of the IMCD (27). The expression of Per1 and Sgk1 was induced after 1 and 24 hours of 

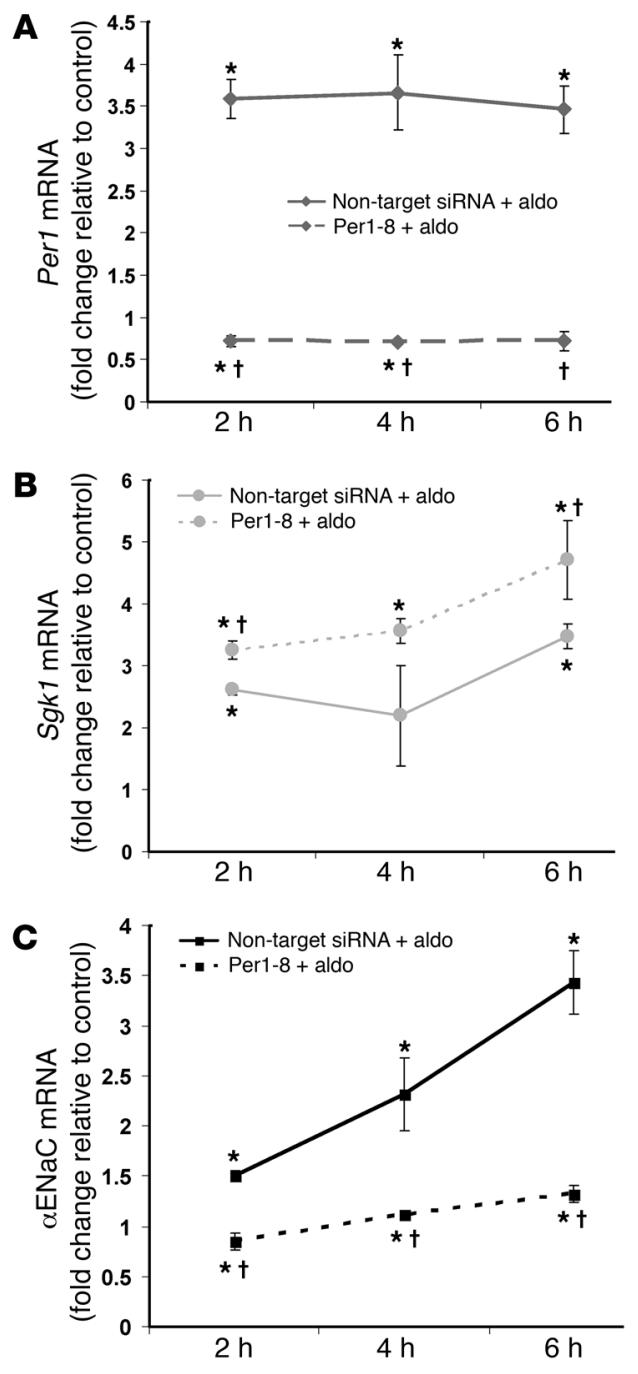

aldosterone treatment, while Per2 expression was upregulated only after 24 hours of aldosterone treatment (Supplemental Figure 1A). $\alpha \mathrm{ENaC}$ expression was upregulated more than 10 -fold after 24 hours of hormone treatment. These results were consistent with what was observed in mIMCD-3 cells (see Figure 2A).

Since the effect of Per1 knockdown on the aldosterone response of $\alpha \mathrm{ENaC}$ mRNA in mIMCD-3 cells was so dramatic, a similar experiment was performed in mIMCD-K2 cells to test the effect in an independent cell line (Supplemental Figure 1B). As was

\section{Figure 7}

Effect of Per1 knockdown on $\alpha \mathrm{ENaC}$ occurs in the early phase of aldosterone action. Mouse IMCD-3 cells were transfected with a non-target siRNA or Per1-8 siRNA for 24 hours and then treated with vehicle or aldosterone for 2, 4, or 6 hours. QPCR was used to analyze changes in gene expression of Per1 (A), Sgk1 (B), and $\alpha \mathrm{ENaC}$ (C) after Per1 knockdown in the presence of aldosterone compared with control (vehicle treated, non-target siRNA-transfected cells; data not shown). Fold change values were normalized against actin relative to the nontarget siRNA-transfected, vehicle-treated control. Data are presented as mean \pm SEM; $n=3$. ${ }^{*} P<0.05$ versus control; ${ }^{\dagger} P<0.05$ versus nontarget siRNA-transfected cells treated with aldosterone.

observed in mIMCD-3 cells, transfection with any of 4 independent Per1-specific siRNAs prevented the induction of Per1 by aldosterone. Sgk1 mRNA levels were increased in Per1-knockdown cells. However, in contrast to what was observed in mIMCD-3 cells, the magnitude of Sgk1 induction in Per1-specific siRNA-transfected mIMCD-K2 cells was less than that in the aldosterone-treated non-target siRNA-transfected cells. The effect of Per1 knockdown on $\alpha \mathrm{ENaC}$ was equivalent in mIMCD-3 cells and mIMCD-K2 cells. The results thus suggest that Per1 knockdown inhibits the response of $\alpha \mathrm{ENaC}$ to aldosterone in mIMCD-K2 cells.

Effect of Per 1 knockdown on $\alpha E N a C$ expression occurs in the early phase of aldosterone action. Aldosterone action occurs in 3 phases. The immediate phase, from minutes to 1 hour, includes genomic and nongenomic effects and involves Sgk1 action on ENaC channel stability. The early phase, from 2 to 6 hours, involves transcriptional induction of genes such as Per 1 and Sgk1. $\alpha$ ENaC levels increase in response to aldosterone toward the end of this period. The late phase of aldosterone action, 6 hours and beyond, involves sustained increases in $\alpha \mathrm{ENaC}$ expression and subsequent increases in channel activity. Our previous experiment demonstrated that Per1 knockdown prevented the late effects of aldosterone on $\alpha \mathrm{ENaC}$. In order to measure the effect of Per1 knockdown on $\alpha \mathrm{ENaC}$ mRNA expression during the early phase of aldosterone action, we performed a time course study. mIMCD-3 cells were transfected with non-target siRNA or Per1-8 siRNA and then treated with vehicle or aldosterone for 2, 4, or 6 hours (Figure 7). QPCR was used to analyze changes in mRNA levels of Per1, Sgk1, and $\alpha E N a C$. Fold change values were calculated relative to non-target siRNA-transfected cells treated with vehicle. In non-target siRNA-transfected cells treated with aldosterone, Per 1 mRNA levels increased more than 3-fold at 2, 4 , or 6 hours of hormone exposure (Figure 7A, solid line). The increase in Per 1 by aldosterone was prevented in cells transfected with the Per1-8 siRNA (Figure 7A, dashed line). Sgk1 mRNA

\section{Figure 8}

$\alpha \mathrm{ENaC}$ expression is inhibited by Per1 knockdown in the absence of aldosterone. Mouse IMCD-3 cells were transfected with a non-target siRNA or Per1-8 siRNA. Forty-eight hours later, total RNA was isolated and processed for QPCR. Fold changes in Sgk1 and $\alpha E N a C$ were normalized against actin relative to the non-target siRNA-transfected cells. Data are presented as mean $\pm \mathrm{SEM} ; n=4 .{ }^{*} P<0.05$ versus nontarget siRNA-transfected cells.

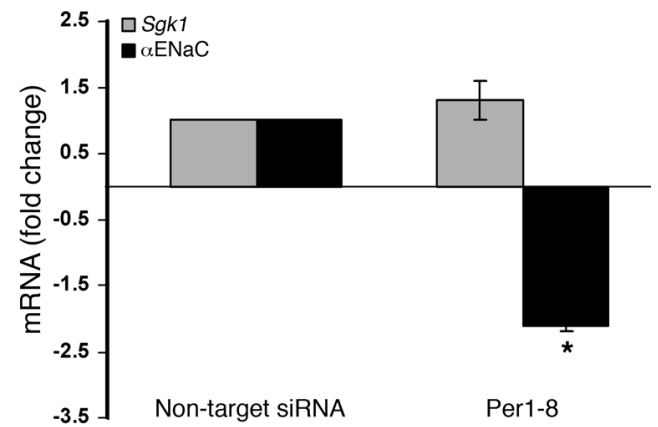

Non-target siRNA Per1-8 


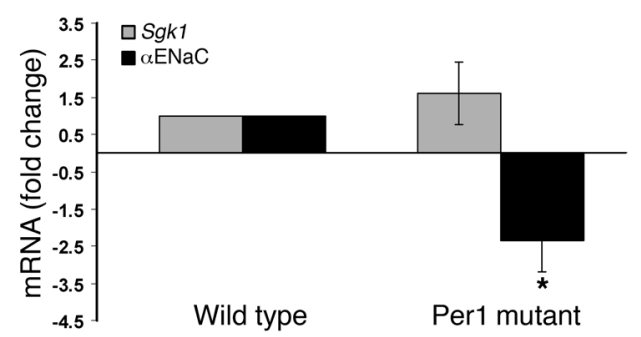

Figure 9

$\alpha \mathrm{ENaC}$ expression is attenuated in the inner medulla of Per1-deficient mice. Total RNA was isolated from the inner medullas of wild-type (129/Sv) or Per1-deficient mice. QPCR was used to analyze changes in gene expression of Sgk1 (gray bars) and $\alpha \mathrm{ENaC}$ (black bars) in Per1deficient compared with wild-type control animals. Fold change values were normalized against actin relative to wild-type control mice. Data are presented as mean $\pm \mathrm{SEM} ; n=3 .{ }^{*} P<0.05$ versus wild-type.

expression increased at all time points of aldosterone treatment (Figure 7B). The increase in Sgk1 by aldosterone was not affected by Per1 knockdown. Indeed, Sgk1 levels were slightly higher in aldosterone-treated cells transfected with Per1-8 siRNA. Surprisingly, $\alpha E N a C$ mRNA levels were significantly increased following 2 hours of aldosterone treatment. The aldosteroneinduced increase in $\alpha \mathrm{ENaC}$ mRNA levels was observed after 4 or 6 hours of hormone treatment (Figure 7C). Interestingly, the early increase in $\alpha E N a C$ mRNA levels was prevented after siRNAmediated knockdown of Per1 (Figure 7C). These data indicate that the effect of Per1 knockdown on the regulation of $\alpha \mathrm{ENaC}$ by aldosterone occurs in the early phase of aldosterone action.

$\alpha E N a C$ expression is inhibited by Per 1 knockdown in the absence of aldosterone. The results of the time course experiment indicated that the effect of Per 1 knockdown on $\alpha E N a C$ occurred within the first 2 hours after aldosterone treatment. This result led to the hypothesis that Per 1 contributes to the basal regulation of $\alpha \mathrm{ENaC}$ expression. To test this, we analyzed changes in $\alpha \mathrm{ENaC}$ expression after Per 1 knockdown in the absence of aldosterone stimulation (Figure 8). mIMCD-3 cells were transfected with a non-target siRNA or Per1-8 siRNA. Per1 mRNA levels were significantly decreased in these cells $(83 \% \pm 3.5 \%)$. Fold change values were calculated relative to the non-target siRNA-transfected control. Sgk 1 levels were unaffected by Per 1 knockdown. However, $\alpha \mathrm{ENaC}$ expression was decreased more than 2-fold after Per1 knockdown in the absence of aldosterone. These data suggest a role for Per1 in the basal regulation of $\alpha \mathrm{ENaC}$ transcription.

\section{Figure 10}

Per1 mediates regulation of $\alpha \mathrm{ENaC}$ expression in the outer medulla. (A) The induction of $\alpha E N a C$ by aldosterone is attenuated in $O M C D_{1}$ cells after Per1 knockdown. OMCD 1 cells were grown, siRNA-transfected, and treated with vehicle or aldosterone as described for mIMCD-3 cells. ${ }^{*} P<0.05$ versus non-target siRNA-transfected cells treated with vehicle; ${ }^{* *} P<0.05$ versus non-target siRNA-transfected cells treated with aldosterone; $n=4$. (B) In the absence of aldosterone, Per1 knockdown results in a 2 -fold decrease in $\alpha$ ENaC mRNA levels in $\mathrm{OMCD}_{1}$ cells. ${ }^{\dagger} P<0.05$ versus non-target siRNA-infected cells; $n=6$. (C) Per1-deficient mice exhibit reduced $\alpha E N a C$ expression in the outer medulla. $¥ P<0.05$ versus wild-type; $n=3$. All data are presented as mean \pm SEM. $\alpha E N a C$ expression is attenuated in Per1 mutant mice. Results from 2 IMCD cell lines led us to hypothesize that Per1 contributes to the regulation of $\alpha \mathrm{ENaC}$ transcription. If Per 1 contributes to the transcriptional regulation of $\alpha \mathrm{ENaC}$, then $\alpha \mathrm{ENaC}$ mRNA levels should be decreased in animals lacking functional Per1. To test this, we evaluated $\alpha \mathrm{ENaC}$ expression in Per1-deficient compared with wild-type mice. Mice with targeted disruption of the Per1 gene have been generated (28). Kidneys from wild-type (129/Sv) mice or Per1 mutant mice were obtained. The inner medullas from wild-type and Per1deficient mice were dissected. QPCR was used to analyze changes in $\alpha \mathrm{ENaC}$ and Sgk1 mRNA levels in Per1-deficient mice compared with wild-type controls (Figure 9). Sgk1 levels were equivalent in the inner medullas of Per1-deficient and wild-type kidneys. Importantly, $\alpha \mathrm{ENaC}$ levels were significantly reduced in the inner medullas of Per1 mutant mice compared with wild-type control mice. The decrease in $\alpha \mathrm{ENaC}$ expression in Per1-deficient mice indicates a role for Per1 in the in vivo regulation of renal $\alpha \mathrm{ENaC}$.

Per 1 mediates regulation of $\alpha E N a C m R N A$ expression in the outer medulla. To evaluate whether the Per1-mediated regulation of $\alpha \mathrm{ENaC}$ expression was limited to the inner medulla, we tested the effect of Per1 knockdown in an in vitro model of the outer medullary collecting duct (OMCD). OMCD 1 cells (29) were grown and transfected with siRNA and treated with vehicle or aldosterone exactly as described for mIMCD-3 cells. The mRNA expression of $\alpha \mathrm{ENaC}$ was dramatically increased by aldosterone in these cells (Figure 10A). The induction of $\alpha \mathrm{ENaC}$ by aldosterone was reduced more than 3-fold after Per1 knockdown in $\mathrm{OMCD}_{1}$ cells. Next, the effect of Per1 knockdown on $\alpha \mathrm{ENaC}$ expression was tested in the
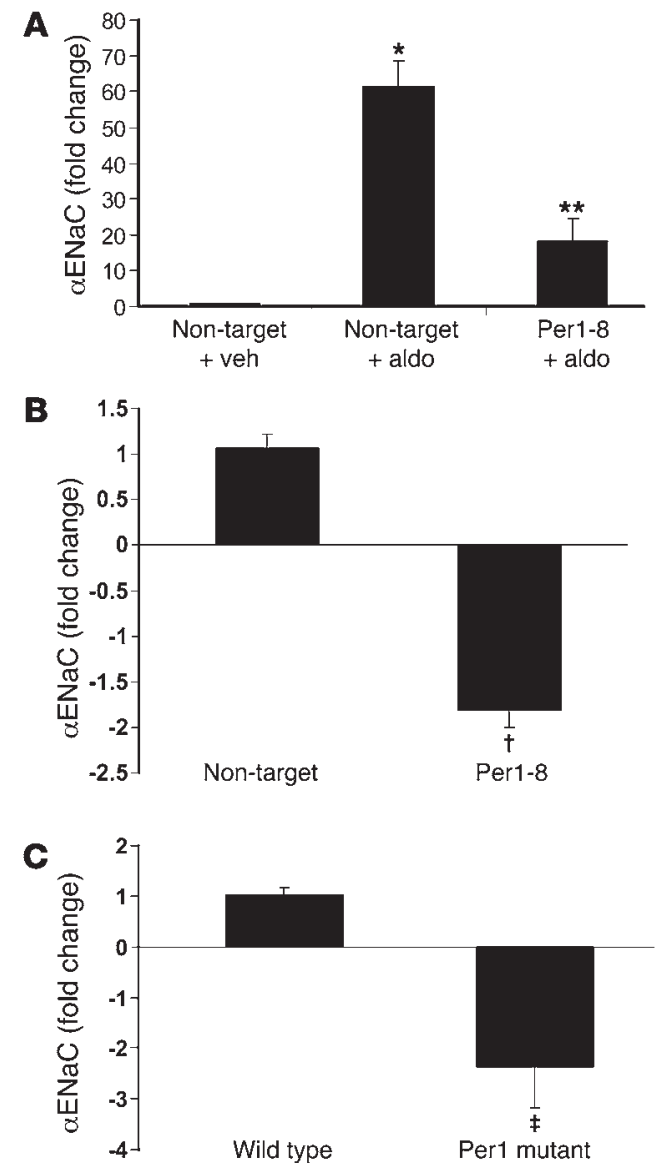

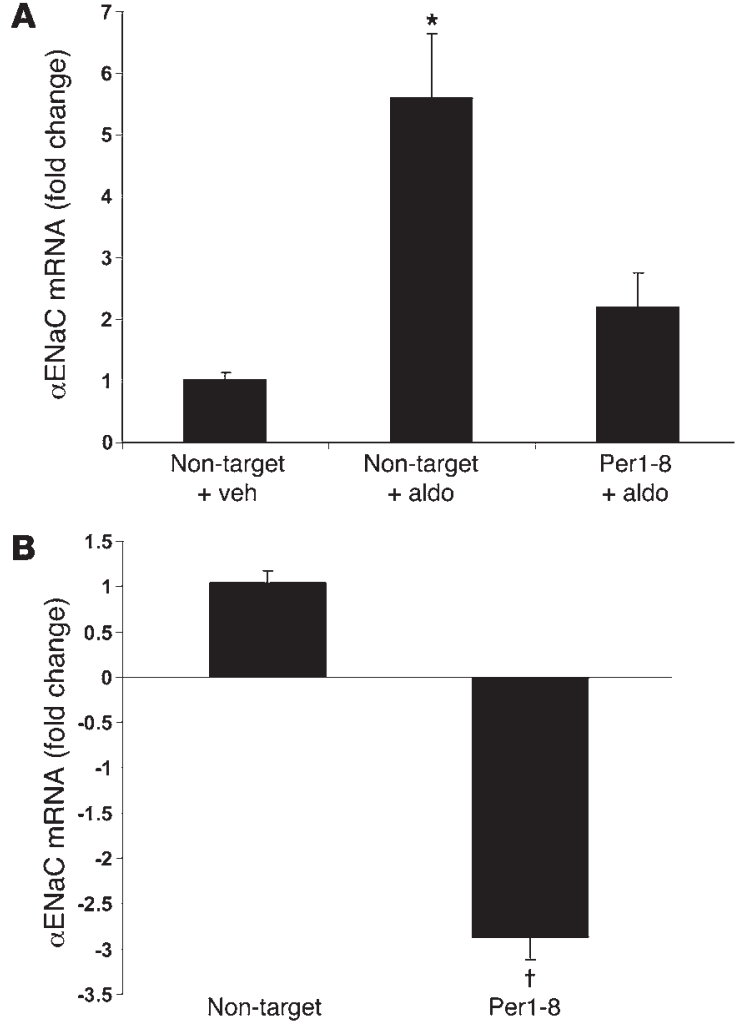

absence of hormone treatment. As was observed in mIMCD-3 cells, Per1 knockdown resulted in a statistically significant decrease in $\alpha \mathrm{ENaC}$ mRNA levels (Figure 10B).

To evaluate the role of Per 1 in the regulation of $\alpha E N a C$ in the outer medulla in vivo, we analyzed $\alpha E N a C$ mRNA levels in the outer medulla of wild-type and Per1-deficient mice. Figure 10C shows that $\alpha \mathrm{ENaC}$ mRNA levels were reduced more than 2 -fold in mice lacking Per1 compared with wild-type mice. These data are consistent with the in vitro and in vivo results from the inner medulla. Thus, there appears to be a role for Per1 in the in vivo regulation of $\alpha \mathrm{ENaC}$ expression in the inner and outer medulla.

Per 1 mediates regulation of $\alpha E N a C m R N A$ expression in $m p k C C D_{c 14}$ cells. To evaluate whether the Per1-mediated regulation of $\alpha E N a C$ expression extended to the cortex, we tested the effect of Per1 knockdown in an in vitro model of the cortical collecting duct (CCD). Murine mpkCCD $\mathrm{cl}_{14}$ cells (30) were grown and transfected with siRNA and treated with vehicle or aldosterone exactly as described for mIMCD-3 cells. Consistent with the work of Bens et al. (30), the mRNA expression of $\alpha E N a C$ was increased by aldosterone in these cells (Figure 11A). As we observed in mIMCD-3 and $\mathrm{OMCD}_{1}$ cells, Per1 knockdown inhibited the induction of $\alpha \mathrm{ENaC}$ by aldosterone. Next, the effect of Per 1 knockdown on $\alpha \mathrm{ENaC}$ expression was tested in the absence of hormone treatment. Again, consistent with our results in mIMCD-3 and $\mathrm{OMCD}_{1}$ cells, knockdown of Per1 led to a nearly 3-fold decrease in $\alpha \mathrm{ENaC}$ mRNA levels (Figure 11B).

Mice lacking functional Per 1 excrete more urinary Na than wild-type mice. To evaluate renal $\mathrm{Na}$ handling in Per1-deficient mice, we performed a metabolic cage study. Twenty-four-hour urine collections were made from Per1-deficient mice or wild-type control mice $(129 / \mathrm{Sv})$ maintained on normal laboratory chow. Body weight
Figure 11

Per1 mediates regulation of $\alpha \mathrm{ENaC}$ expression in the cortex. (A) The induction of $\alpha \mathrm{ENaC}$ by aldosterone is attenuated in mpkCCD $\mathrm{c}_{\mathrm{c} 14}$ cells after Per1 knockdown. mpkCCD ${ }_{\mathrm{c} 14}$ cells were grown, siRNA-transfected, and treated with vehicle or aldosterone as described for mIMCD-3 cells. ${ }^{*} P<0.05$ versus non-target siRNA-transfected cells treated with vehicle; $n=4$. (B) In the absence of aldosterone, Per1 knockdown results in a 2-fold decrease in $\alpha E N a C$ mRNA levels in mpkCCD ${ }_{c 14}$ cells. ${ }^{\dagger} P<0.05 ; n=6$. All data are presented as mean \pm SEM.

was not significantly different between wild-type $(34.6 \pm 1.6 \mathrm{~g})$ and Per1-deficient $(32.8 \pm 1.9 \mathrm{~g})$ mice $(P=0.5)$. Food and water intake tended to be higher in Per1-deficient mice $(5.7 \pm 1.1 \mathrm{~g}$; $6.5 \pm 1.4 \mathrm{ml})$ compared with wild-type mice $(4.3 \pm 0.6 \mathrm{~g} ; 4.8 \pm 0.5$ $\mathrm{ml})$, but this trend did not reach significance $(P=0.32$ for food intake; $P=0.25$ for water intake). Urinary $\mathrm{Na}$ and chloride $(\mathrm{Cl})$ excretion were evaluated (Figure 12, A and B), and total urine volume was measured (Figure 12C). Cl excretion tended to be higher in Per1-deficient mice compared with control animals, but this difference was not significant. Importantly, statistically significant increases in urinary $\mathrm{Na}$ excretion and urine output were observed in mice lacking Per1 compared with wild-type mice. This observation is consistent with our in vivo data demonstrating decreased renal $\alpha E N a C$ expression in Per1-deficient mice.

$m R N A$ expression profile of $\alpha E N a C$ is altered in Period-deficient mice. Perhaps the best test of the hypothesis that $\alpha \mathrm{ENaC}$ is regulated by the circadian clock in vivo is to evaluate the 24-hour expression profile of $\alpha \mathrm{ENaC}$ in wild-type compared with Period-deficient mice. To our knowledge, the 24-hour expression profile of $\alpha \mathrm{ENaC}$ mRNA has never been measured in the kidney. Kidneys from wildtype mice or mice lacking functional Per1, Per2, and Per3 (triple knockouts, or TKO) were collected every 4 hours over a 24 -hour period. The TKO mice have been described (31) and provide the best tool for evaluating the role of this family of circadian clock proteins in the regulation of $\alpha \mathrm{ENaC}$. We show that $\alpha \mathrm{ENaC}$ mRNA expression fluctuates with an apparent circadian pattern that is similar to that of Per1 in the inner medulla (Figure 13A), the outer medulla (Figure 13B), and the cortex (Figure 13C) of wild-type mice. At some time points, $\alpha \mathrm{ENaC}$ expression was higher in the TKO compared with wild-type animals ( $\Delta \mathrm{Ct}$ is an inverse measure of relative expression). Because this experiment does not distinguish among the effects of Per1, Per2, and Per3, the implications of this outcome are unclear. Interestingly, the peak of $\alpha \mathrm{ENaC} \mathrm{mRNA}$ expression was shifted by 12 hours in each segment of the kidney in TKO mice compared with wild type. In the inner medulla, wild-type $\alpha E N a C$ expression peaked at circadian time 10 (CT10), while TKO $\alpha E N a C$ peaked at CT22. In the outer medulla, $\alpha E N a C$ expression peaked at CT18 in wild-type mice compared with CT6 in the TKO mice. $\alpha \mathrm{ENaC} \mathrm{mRNA}$ levels peaked at CT2 in the cortex of TKO mice versus CT14 in the wild-type mice.

To evaluate differences in the 24-hour expression profile of renal $\alpha E N a C$ in mice lacking functional Period genes compared with wild-type mice, we generated scatter plots using the mean $\Delta C t$ values at each time point for $\alpha E N a C$ expression in each renal segment for wild-type and TKO mice. Waveform functions were then fitted to the data (Supplemental Figure 2). The results for the inner medulla and outer medulla show that loss of the Period genes resulted in an inversion of the expression profile for $\alpha \mathrm{ENaC}$. The expression profile for $\alpha \mathrm{ENaC}$ in the wild-type cortex was very similar to that in the inner and outer medulla. In the TKO cortex, 

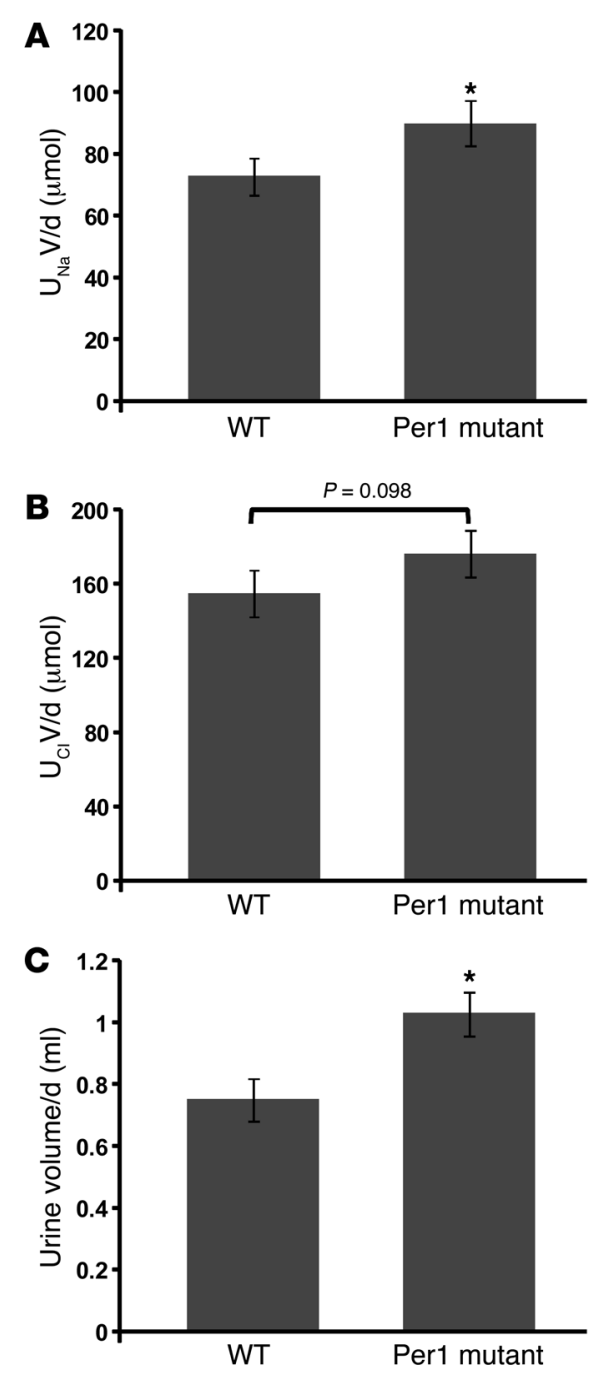

however, the pattern appeared to be reversed in the time period tested. Together, these data demonstrate that the 24-hour $\alpha \mathrm{ENaC}$ expression profile is dramatically altered in the inner medulla, the outer medulla and the cortex of mice lacking the 3 Period genes compared with wild-type mice. This result provides compelling evidence supporting the hypothesis that the circadian clock regulates in vivo $\alpha \mathrm{ENaC} \mathrm{mRNA}$ expression.

\section{Discussion}

Here we show for the first time to our knowledge that $\alpha \mathrm{ENaC}$ mRNA expression is regulated by the aldosterone-responsive circadian clock gene Per1 in the kidney. These data provide a direct molecular link between the circadian clock and a mediator of renal Na transport. Per1 knockdown prevented the response of $\alpha \mathrm{ENaC}$ to aldosterone in several renal collecting duct cell lines representing the IMCD, OMCD, and CCD. In addition, $\alpha E N a C$ levels were decreased after Per1 knockdown in the absence of hormonal stimulation in these cell lines. Furthermore, $\alpha E N a C$ mRNA levels were reduced in the inner medulla and outer medulla in vivo in Per1-deficient mice. Consistent with this observation, the Per1-deficient mice exhibited higher urinary $\mathrm{Na}$ excretion. Most strikingly, we show that $\alpha \mathrm{ENaC}$ mRNA appears to be

\section{Figure 12}

Mice lacking Per1 excrete more sodium compared with wild-type mice. Per1 mutant mice $(n=3)$ or wild-type mice $(n=4)$ were housed in metabolic cages and maintained on a normal laboratory chow diet with free access to water for 48 hours. Food and water intake and body weight were monitored. Two 24-hour urine collections were made. Urine was analyzed for $\mathrm{Na}\left(\mathrm{U}_{\mathrm{Na}} \mathrm{V} ; \mathbf{A}\right), \mathrm{Cl}\left(\mathrm{U}_{\mathrm{Cl}} \mathrm{V}, \mathrm{B}\right)$, and total volume $(\mathbf{C}) .{ }^{*} P<0.05$ versus wild-type. Data are presented as mean \pm SEM.

expressed in a pattern very similar to that of the circadian rhythm gene Per 1 in wild-type mice and that this expression profile is altered in mice lacking functional Period genes. This novel observation could have major implications for renal $\mathrm{Na}$ handling, and possibly blood pressure control.

Our report of the upregulation of Per 1 by aldosterone is consistent with in vitro work concerning regulation of Per1 by the renin angiotensin aldosterone system (RAAS). Microarray analysis in a human adrenocortical cell line after angiotensin II treatment demonstrated that Per1 was upregulated 3-fold compared with control (24). Per 1 and Per 2 were induced by aldosterone in cardiomyoblasts, an effect that was blocked by spironolactone (32). Another connection between hormone signaling and Per1 was demonstrated by Balsalobre et al. They found that glucocorticoids reset circadian timing in peripheral tissues, including the kidney, by inducing the expression of Per1 (33).

Of particular note, $S g k 1$ mRNA levels were unaffected by Per1 knockdown in mIMCD-3 cells or in the inner medulla of Per1-deficient mice and were only slightly decreased following Per1 knockdown in mIMCD-K2 cells. Sgk1 is considered a canonical regulator of $\mathrm{ENaC}$, yet evidence suggests that $\mathrm{Sgk} 1$ is not solely responsible for mediating aldosterone action on ENaC. For example, Sgk1knockout mice have a much milder $\mathrm{Na}$ wasting phenotype than MR-knockout mice (34-37). Furthermore, ENaC function is fully upregulated by chronic aldosterone exposure in Sgk1-knockout mice (37), suggesting that other mediators of aldosterone action can stimulate ENaC. Together with our demonstration of the role of Per1 in regulating $\alpha \mathrm{ENaC}$ expression, these in vivo studies suggest that Per1 action is not likely to be downstream of Sgk1. Since Sgk1 mRNA levels are not affected by Per1 knockdown, it seems unlikely that Sgk1 is directly downstream of Per1 action. It remains to be seen whether Per1 action is truly independent of Sgk1. Given the results in the mIMCD-K2 cells, which are derived from a more proximal region than mIMCD-3 cells, it is possible that the sequence of regulatory events could differ depending on the specific region of the nephron.

Perhaps the most intriguing implication of these findings concerns the known role of $\mathrm{ENaC}$ in the maintenance of blood pressure. Underscoring the importance of $\mathrm{ENaC}$ in blood pressure regulation is the fact that gain-of-function mutations in $\mathrm{ENaC}$ subunits cause the hypertensive disorder Liddle syndrome. Conversely, loss-of-function mutations in $\mathrm{ENaC}$ subunits result in the hypotensive disorder pseudohypoaldosteronism type 1a. Aldosterone is known to be secreted with a diurnal pattern, as it increases during sleep (38). The connection among the circadian clock, aldosterone signaling, and $\alpha \mathrm{ENaC}$ expression is especially interesting given the well-characterized diurnal pattern of blood pressure. Blood pressure increases in the early morning, and this is followed by a plateau during active daytime and then a "dip" in values during sleep (39). Patients who do not exhibit this dipping pattern are designated "non-dippers." There is extensive evidence sup- 

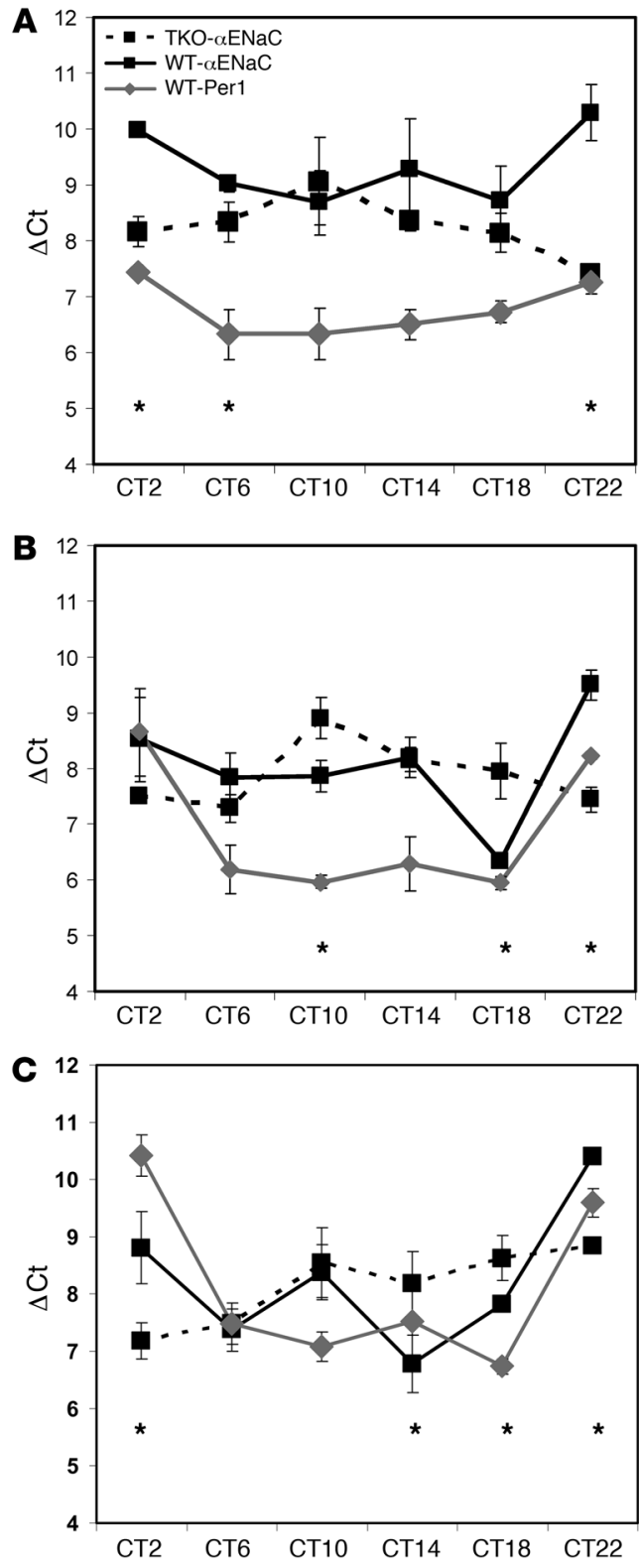

porting a role for the kidney and $\mathrm{Na}$ homeostasis in maintenance of the circadian rhythm of blood pressure (40-42). For example, the dipping pattern can be restored after renal transplantation (43). Furthermore, there are several reports linking RAAS and aldosterone signaling and non-dipping $(44,45)$. Patients suffering from hyperaldosteronism exhibit the non-dipper pattern $(46,47)$. The mechanism of how the circadian clock affects physiological processes is an active area of investigation. Gene profiling experiments in tissues such as liver and heart have shown that $6 \%-8 \%$ of expressed genes are subject to circadian control (reviewed in ref. 9). Presumably, this involves regulation of targets by circadian clock proteins or their direct effectors. The importance of the circadian clock in regulation of physiological processes such as renal and cardiac function is clear. However, the underlying molecular mechanisms are largely unknown. It was recently demonstrated that hamsters with a disrupted circadian rhythm display severe

\section{Figure 13}

The expression profile of $\alpha \mathrm{ENaC}$ is altered in Period-deficient mice. Inner medullas (A), outer medullas (B), and cortex (C) were dissected from 3 wild-type or 3 TKO mice that were euthanized every 4 hours over a 24-hour period. Total RNA was isolated and converted to cDNA for QPCR analysis. The data are expressed as the $\Delta \mathrm{Ct}$ value, which is a measure of expression relative to actin (higher $\Delta \mathrm{Ct}$ values correspond to lower expression; see ref. 49), versus the circadian time (CT2-CT22). Data are presented as mean \pm SEM; $n=3$ for each data point. ${ }^{*} P<0.05$, wild-type $\alpha \mathrm{ENaC}$ expression versus TKO.

renal and cardiac disease (48). These hamsters have a mutation in the gene for casein kinase-1ع, a kinase that directly phosphorylates Per1, leading to Per1 degradation (8).

In conclusion, we have shown for the first time to our knowledge that Per 1 is regulated by aldosterone and in turn mediates aldosterone action on the expression of $\alpha \mathrm{ENaC}$ mRNA. Importantly, the effect of Per1 knockdown on $\alpha E N a C$ occurred even in the absence of aldosterone stimulation and was observed in Per1-deficient mice as well. These data suggest a new pathway for regulation of $\alpha \mathrm{ENaC}$ by the circadian clock. This observation could lead to the first characterization of a molecular regulator of circadian blood pressure patterns.

\section{Methods}

Animals. All animal experiments were approved by the University of Florida Institutional Animal Care and Use Committee. Male Sprague-Dawley rats (290-320 g; Harlan) were given an i.p. injection ( $1 \mathrm{ml} / \mathrm{kg}$ ) of aldosterone $(1 \mathrm{mg} / \mathrm{kg})$ or vehicle (20 $\mu \mathrm{l} \mathrm{ethanol} / \mathrm{kg}$ in saline). After 1,2 , or 6 hours, rats were anesthetized with isoflurane, and the aorta was cannulated with a 19G winged infusion set. After blood collection into an EDTA-coated syringe, the kidneys were immediately flushed by in vivo aortic perfusion of PBS ( $\mathrm{pH} 7.4)$ with the vena cava vented. The right kidney was removed and the inner medulla dissected before being flash frozen in liquid nitrogen.

Kidneys from Per1-deficient mice, TKO mice, and wild-type controls were collected at the University of Massachusetts Medical School. These animals have been described previously $(28,31)$.

Metabolic study. Metabolic cage studies were performed at the University of Massachusetts Medical School with approval from and in accordance with the local IACUC. Per1-deficient mice and 129/Sv mice were acclimated to metabolic cages (Lab Products) for 3 days before two 24-hour urine samples were collected. Animals had free access to standard laboratory chow and water. Body weight and food and water intake were measured. Urinary $\mathrm{Na}$ and $\mathrm{Cl}$ content were measured using a Nova 16 Electrolyte/Chemistry Analyzer (Nova Biomedical).

Cell culture. mIMCD-3 cells were purchased from ATCC. Mouse IMCD-K2 cells were a gift from Bruce Stanton (Dartmouth Medical School, Hanover, New Hampshire, USA) (27). $\mathrm{OMCD}_{1}$ cells were a gift from Thomas DuBose (Wake Forest University, Winston-Salem, North Carolina, USA) (29). Alain Vandewalle (INSERM, Paris, France) provided the mpkCCD ${ }_{c 14}$ cells (30). Cells were maintained in DMEM-F12 plus $10 \% \mathrm{FBS}$ and $50 \mu \mathrm{g} / \mathrm{ml}$ gentamicin. For aldosterone treatments, 600,000 cells were plated in each well of a 6-well Corning Costar Transwell dish. Twenty-four hours after cells reached $100 \%$ confluency, the medium was changed to phenol red-free DMEM-F12 (Invitrogen) plus 10\% charcoal/dextran-treated FBS to deprive the cells of steroid hormones. Another 24 hours later, cells were treated with vehicle (ethanol) or $1 \mu \mathrm{M}$ aldosterone for varying time intervals. Final ethanol concentration in both vehicle and aldosterone-treated cells was $0.1 \%$.

$R N A$ isolation and QPCR. Total RNA was isolated using TRIzoL (Invitrogen) according to the manufacturer's instructions. RNA samples $(10 \mu \mathrm{g})$ were 
Table 2

Taqman assays used for quantitative real time PCR

\begin{tabular}{lccc} 
Gene & \multicolumn{1}{c}{ Reporter sequence } & Assay IDA & $\begin{array}{c}\text { Amplicon } \\
\text { length (bp) }\end{array}$ \\
Per1 & CCTCAGCCCCTGGCTGCCACCATGG & Mm00501813_m1 & 106 \\
Per2 & CACCTCCAACATGCAACGAGCCCTC & Mm00478113_m1 & 73 \\
Actin & TACTGAGCTGCGTTTACACCCTTT & Mm00607939_s1 & 115 \\
Scnn1a $(\alpha$ ENaC) & CGGCTTCCAACTGTGCAACCAGAC & Mm00803386_m1 & 69 \\
Nr3c1 $(\mathrm{GR})$ & ATGGATATTCAAGCCCTGGAATGAG & Mm00433832_m1 & 68 \\
Nr3c2 $(\mathrm{MR})$ & GACTCCATGCATGATTTGGTGAATG & Mm01241597_m1 & 92 \\
Sgk1 & CAAACACGCTGAAGTTCAGTCCATT & Mm00441380_m1 & 71 \\
\hline
\end{tabular}

APurchased from Applied Biosystems.
USA) (23), pCMVSport6, or pCMVSport6-Per1 (gifts from Damian Romero, The University of Mississippi Medical Center, Jackson, Mississippi, USA) (24) or the promoter-less negative control plasmid pGL3 using FuGENE (Roche) according to the manufacturer's instructions. Transfection efficiency was normalized in all cells by cotransfection with identical amounts of the plasmid pRL-TK, containing Renilla luciferase cDNA. After transfection (24 hours), cells were treated with vehicle or $1 \mu \mathrm{M}$ aldosterone for 6 hours. Dual luciferase assays (Promega) were performed according to the manufacturer's instructions.

Analysis of hnRNA. Analysis of the short-lived hnRNA is a measure of transcriptional activity treated with DNA-free DNaseI (Ambion). DNaseI-treated RNA (2 $\mu \mathrm{g})$ samples were used as template for reverse transcription with Superscript III (Invitrogen). The resulting cDNAs (20 ng) were then used as templates in duplicate QPCR reactions (Applied Biosystems) to evaluate changes in expression of several transcripts. Ct values were normalized against actin mRNA, and relative quantification was performed using the $\Delta \Delta \mathrm{Ct}$ method (49). Fold change values were calculated as the change in mRNA expression levels relative to the vehicle-treated control. Primer/probe sets were purchased from Applied Biosystems (Table 2).

Western blot analysis. mIMCD-3 cells were treated with vehicle or $1 \mu \mathrm{M}$ aldosterone for 6 hours. Total cell lysates were collected in $1 \times$ passive lysis buffer (Promega). Concentrations were determined using the BCA (bicinchoninic acid) assay (Pierce). Lysates were separated on a 10\%-20\% Tris- $\mathrm{HCl}$ Ready Gel (Bio-Rad). Proteins were transferred to a PVDF membrane. The membrane was blocked in Zymed blocking solution (Invitrogen) and then incubated overnight at $4^{\circ} \mathrm{C}$ with the anti-Per1 primary antibody (Affinity BioReagents) in Zymed solution. The HRP-conjugated rabbit anti-goat secondary antibody (Jackson ImmunoResearch Laboratories Inc.) incubation was performed in Zymed solution for 1 hour at room temperature. After the primary and secondary antibody incubations, the blot was washed in TBS-Tween 3 times for at least 10 minutes. Detection was performed using Rodeo Sensitive detection reagents (USB).

Cloning of the Per1 promoter and luciferase assay. A BAC clone was purchased from BACPAC CHORI. The clone, RP24-277K16, contained $150 \mathrm{~kb}$ of mouse chromosome 11 thought to include the Per 1 gene. The presence of Per1 in clone RP24-277K16 was confirmed by Southern blot analysis. The BAC clone was digested with EcoRI, yielding multiple fragments. A $20-\mathrm{kb}$ EcoRI fragment was expected to contain the Per 1 gene based on sequence analysis of mouse chromosome 11 (obtained at http://www. ncbi.nlm.nih.gov/; Gene ID 18626). A probe based on exon 1 of the Per1 cDNA hybridized to the 20-kb band and to the uncut BAC DNA (data not shown). Using sequence from mouse chromosome 11, we designed the primers MG 92 (5'-CCTGTGGCCCAGGTATCCTCCCTGAAAAGG-3') and MG 93 (5'-GTCTGGGCCATACAGTGGAGGACGAAACAG-3') to amplify a 2,002-bp fragment of the Per 1 gene that extended to the base immediately $5^{\prime}$ of the translation start site (up to but not including the ATG). The PCR product was amplified using the BAC clone DNA as template. The 2,002-bp band was excised, gel purified, and cloned into PCR2.1 TOPO (Invitrogen) for sequence analysis. The nucleotide sequence of the PCR product exactly matched that from the Per1 gene in mouse chromosome 11 (data not shown). A KpnI/XhoI fragment containing the 2,002-bp PCR product was subcloned from pCR2.1 TOPO to PGL3 (Promega) to direct expression of the firefly luciferase reporter gene to generate the Per1/ luc construct. mIMCD-3 cells were transiently transfected with Per1/luc, $\alpha \mathrm{ENaC}$ luc (gift from Christie Thomas, University of Iowa, Iowa City, Iowa,
$(19,50)$. Primers were designed to amplify a 191-bp region spanning the exon7/intron 7 boundary of the Per 1 gene. The forward primer sequence was: 5'-GGTTCAGGTCTCAAGGACTTCACCC-3'. The reverse primer sequence was: $5^{\prime}$-GGGAGAGACGAATATTAGAGGTTTCC-3'. $\alpha$ ENaC hnRNA primer sequences were designed to amplify a 238-bp product spanning exon $6 /$ intron 6 of the Scnn1a gene. The forward primer sequence was 5'-GGAGGCAACTACGGAGACTG-3'. The reverse primer sequence was $5^{\prime}$-GAGAAGCAAGAGGCTTCAGG-3'. GAPDH primers were used as a control for aldosterone treatment and were designed to amplify an 874-bp cDNA fragment. The forward primer sequence was 5'-AGACACGATGGTGAAGGTCGGAGTGAAC-3'. The reverse primer sequence was 5'-GTGGCACTGTTGAAGTCGCAGGAG-3'. Total RNA was isolated from vehicle- and aldosterone-treated cells and DNase I treated as described above. DNase I-treated RNA was incubated with master mix containing reverse transcription and PCR components for 30 minutes at $50^{\circ} \mathrm{C}$. PCR reactions were performed using $40 \mathrm{ng}$ of cDNA as template and the following cycling parameters: Reactions were heated to $95^{\circ} \mathrm{C}$ for 15 minutes to activate the Taq polymerase. Thirty (Per1) or $35(\alpha \mathrm{ENaC})$ amplification cycles were performed using the following parameters: $95^{\circ} \mathrm{C}$ for $30 \mathrm{sec}$ onds, $55^{\circ} \mathrm{C}$ for 30 seconds, $72^{\circ} \mathrm{C}$ for 1 minute, followed by a final 10 -minute extension at $72^{\circ} \mathrm{C}$.

Analysis of Scnn1a promoter. The mouse Scnn1a promoter (GenBank AF346304) was analyzed using TF Search (http://www.cbrc.jp/research/ db/TFSEARCH.html). E box motifs (TRANSFAC accession numbers M00065, M00066, and M00070) with a threshold score of 75 or greater were reported.

RNA silencing. For siRNA experiments, mIMCD-3 cells were plated at a density of 75,000 cells $/ \mathrm{cm}^{2}$ in Transwell dishes in DMEM-F12 medium containing $10 \% \mathrm{FBS}$ and $50 \mu \mathrm{g} / \mathrm{ml}$ gentamicin. At the time of transfection, medium was changed to DMEM-F12 without phenol red containing $10 \%$ charcoal-stripped FBS and no antibiotic. Cells were transfected for 24 hours with siRNA directed against MR, GR, or Per1 (SMARTpool siRNA; Dharmacon) using $2 \mu \mathrm{M}$ siRNA in $6 \mu \mathrm{l}$ of Dharmafect Reagent 4 per well and a final siRNA concentration of $0.067 \mu \mathrm{M}$. Twenty-four hours after transfection, cells were treated with vehicle or aldosterone for various time points.

Statistics. One-way ANOVA was performed with the Bonferroni test for error protection, with the exception of the time course data in Figure 13, for which a 2-way ANOVA with the Tukey test was used. Data are presented as mean \pm SEM or SD as designated. $P$ values less than 0.05 were considered significant.

\section{Acknowledgments}

The authors acknowledge Robert Dallmann for collection of kidneys from Per-deficient mice; Bruce Stanton for the mIMCD-K2 
cells; Thomas DuBose for the $\mathrm{OMCD}_{1}$ cells; Alain Vandewalle for the mpkCCD ${ }_{c 14}$ cells; Damian Romero for the Per1 expression construct; and Christie Thomas for the $\alpha \mathrm{ENaC}$ promoter luciferase construct. This work was supported by grants from the NIDDK (R01 DK049750 to C.S. Wingo and T32 DK-07518 and AHA 0825467E to M.L. Gumz) and by the Department of Veterans Affairs (C.S. Wingo and M.L. Gumz).

1. Goodfriend, T.L. 2006. Aldosterone - a hormone of cardiovascular adaptation and maladaptation. J. Clin. Hypertens. (Greenwich). 8:133-139.

2. Pitt, B. 2004. Effect of aldosterone blockade in patients with systolic left ventricular dysfunction: implications of the RALES and EPHESUS studies. Mol. Cell. Endocrinol. 217:53-58.

3. Booth, R.E., Johnson, J.P., and Stockand, J.D. 2002. Aldosterone. Adv. Physiol. Educ. 26:8-20.

4. Gumz, M.L., Popp, M.P., Wingo, C.S., and Cain, B.D. 2003. Early transcriptional effects of aldosterone in a mouse inner medullary collecting duct cell line. Am. J. Physiol. Renal Physiol. 285:F664-F673.

5. Escoubet, B., Coureau, C., Bonvalet, J.P., and Farman, N. 1997. Noncoordinate regulation of epithelial $\mathrm{Na}$ channel and $\mathrm{Na}$ pump subunit mRNAs in kidney and colon by aldosterone. Am. J. Physiol. 272:C1482-C1491.

6. Beutler, K.T., et al. 2003. Long-term regulation of $\mathrm{ENaC}$ expression in kidney by angiotensin II. Hypertension. 41:1143-1150.

7. Takahashi, J.S. 1991. Circadian rhythms: from gene expression to behavior. Curr. Opin. Neurobiol. 1:556-561.

8. Albrecht, U. 2004. The mammalian circadian clock: a network of gene expression. Front. Biosci. 9:48-55.

9. Albrecht, U., and Eichele, G. 2003. The mammalian circadian clock. Curr. Opin. Genet. Dev. 13:271-277.

10. Pons, M., Cambar, J., and Waterhouse, J.M. 1996. Renal hemodynamic mechanisms of blood pressure rhythms. Ann. N. Y. Acad. Sci. 783:95-112.

11. Manchester, R.C. 1933 . The diurnal rhythm in water and mineral exchange. J. Clin. Invest. 12:995-1008.

12. Wesson, L.G.,Jr., and Lauler, D.P. 1961. Diurnal cycle of glomerular filtration rate and sodium and chloride excretion during responses to altered salt and water balance in man. J. Clin. Invest. 40:1967-1977.

13. Stanbury, S.W., and Thomson, A.E. 1951. Diurnal variation in electrolyte excretion. Clin. Sci. (Lond.). 10:267-293.

14. Dyer, A.R., Martin, G.J., Burton, W.N., Levin, M., and Stamler, J. 1998. Blood pressure and diurnal variation in sodium, potassium, and water excretion. J. Hum. Hypertens. 12:363-371.

15. Goldman, R. 1951. Studies in diurnal variation of water and electrolyte excretion; nocturnal diuresis of water and sodium in congestive cardiac failure and cirrhosis of the liver. J. Clin. Invest. 30:1191-1199.

16. Pearce, D., and Kleyman, T.R. 2007. Salt, sodium channels, and SGK1. J. Clin. Invest. 117:592-595.

17. Verrey, F., et al. 2000. Pleiotropic action of aldosterone in epithelia mediated by transcription and post-transcription mechanisms. Kidney Int. 57:1277-1282.

18. Yu, L., Bao, H.F., Self, J.L., Eaton, D.C., and Helms, M.N. 2007. Aldosterone-induced increases in superoxide production counters nitric oxide inhibition of epithelial $\mathrm{Na}$ channel activity in A6 distal nephron cells. Am. J. Physiol. Renal Physiol. 293:F1666-F1677.

19. Lipson, K.E., and Baserga, R. 1989. Transcriptional activity of the human thymidine kinase gene deter-
Received for publication July 25, 2008, and accepted in revised form May 13, 2009.

Address correspondence to: Charles S. Wingo, 1600 SW Archer Road, Division of Nephrology, Box 100224, Gainesville, Florida 32610, USA. Phone: (352) 376-1611 ext. 4152; Fax: (352) 374-6170; E-mail: cswingo@ufl.edu. mined by a method using the polymerase chain reaction and an intron-specific probe. Proc. Natl. Acad. Sci. U. S. A. 86:9774-9777.

20. Husted, R.F., Laplace, J.R., and Stokes, J.B. 1990. Enhancement of electrogenic $\mathrm{Na}+$ transport across rat inner medullary collecting duct by glucocorticoid and by mineralocorticoid hormones. J. Clin. Invest. 86:498-506.

21. Staruschenko, A., Adams, E., Booth, R.E., and Stockand, J.D. 2005. Epithelial Na+ channel subunit stoichiometry. Biophys. J. 88:3966-3975.

22. Masilamani, S., Kim, G.H., Mitchell, C., Wade, J.B., and Knepper, M.A. 1999. Aldosterone-mediated regulation of $\mathrm{ENaC}$ alpha, beta, and gamma subunit proteins in rat kidney. J. Clin. Invest. 104:R19-R23.

23. Thomas, C.P., Liu, K.Z., and Vats, H.S. 2006 Medroxyprogesterone acetate binds the glucocorticoid receptor to stimulate alpha-ENaC and sgk1 expression in renal collecting duct epithelia. Am.J. Physiol. Renal Physiol. 290:F306-F312.

24. Romero, D.G., et al. 2007. Adrenal transcription regulatory genes modulated by angiotensin II and their role in steroidogenesis. Physiol. Genomics. 30:26-34.

25. Zhang, W., et al. 2006. Aldosterone-sensitive repression of ENaCalpha transcription by a histone $\mathrm{H} 3$ lysine-79 methyltransferase. Am. J. Physiol. Cell Physiol. 290:C936-C946.

26. Zhang, W., et al. 2007. Aldosterone-induced Sgk1 relieves Dot1a-Af9-mediated transcriptional repression of epithelial $\mathrm{Na}+$ channel alpha. J. Clin. Invest. 117:773-783

27. Kizer, N.L., Lewis, B., and Stanton, B.A. 1995. Electrogenic sodium absorption and chloride secretion by an inner medullary collecting duct cell line (mIMCD-K2). Am. J. Physiol. 268:F347-F355.

28. Bae, K., et al. 2001. Differential functions of mPer1, $\mathrm{mPer} 2$, and mPer3 in the SCN circadian clock. Neu ron. 30:525-536.

29. Guntupalli, J., Onuigbo, M., Wall, S., Alpern, R.J., and DuBose, T.D., Jr. 1997. Adaptation to low-K+ media increases $\mathrm{H}(+)-\mathrm{K}(+)$-ATPase but not $\mathrm{H}(+)$ ATPase-mediated pHi recovery in OMCD1 cells. Am. J. Physiol. 273:C558-C571.

30. Bens, M., et al. 1999. Corticosteroid-dependent sodium transport in a novel immortalized mouse collecting duct principal cell line. J. Am. Soc. Nephrol. 10:923-934.

31. Bae, K., and Weaver, D.R. 2007. Transient, lightinduced rhythmicity in mPer-deficient mice. J. Biol. Rhythms. 22:85-88.

32. Tanaka, K., et al. 2007. Aldosterone induces circadian gene expression of clock genes in $\mathrm{H} 9 \mathrm{c} 2$ cardiomyoblasts. Heart Vessels. 22:254-260.

33. Balsalobre, A., et al. 2000. Resetting of circadian time in peripheral tissues by glucocorticoid signaling. Science. 289:2344-2347.

34. McDonald, F.J. 2008. A new SGK1 knockout mouse. Am. J. Physiol. Renal Physiol. 294:F1296-F1297.

35. Wulff, P., et al. 2002. Impaired renal $\mathrm{Na}(+)$ retention in the sgk1-knockout mouse. J. Clin. Invest.
110:1263-1268

36. Berger, S., Bleich, M., Schmid, W., Greger, R., and Schutz, G. 2000. Mineralocorticoid receptor knockout mice: lessons on $\mathrm{Na}+$ metabolism. Kidney Int. 57:1295-1298.

37. Fejes-Toth, G., Frindt, G., Naray-Fejes-Toth, A., and Palmer, L.G. 2008. Epithelial $\mathrm{Na}+$ channel activation and processing in mice lacking SGK1. Am.J. Physiol. Renal Physiol. 294:F1298-F1305.

38. Charloux, A., Gronfier, C., Lonsdorfer-Wolf, E., Piquard, F., and Brandenberger, G. 1999. Aldosterone release during the sleep-wake cycle in humans. Am. J. Physiol. 276:E43-E49.

39. White, W.B. 2000. Ambulatory blood pressure monitoring: dippers compared with non-dippers. Blood Press. Monit. 5(Suppl. 1):S17-S23.

40. Uzu, T., and Kimura, G. 1999. Diuretics shift circadian rhythm of blood pressure from nondipper to dipper in essential hypertension. Circulation. 100:1635-1638.

41. Fukuda, M., Goto, N., and Kimura, G. 2006. Hypothesis on renal mechanism of non-dipper pattern of circadian blood pressure rhythm. Med. Hypotheses. 67:802-806.

42. Portaluppi, F., Montanari, L., Massari, M., Di Chiara, V., and Capanna, M. 1991. Loss of nocturnal decline of blood pressure in hypertension due to chronic renal failure. Am. J. Hypertens. 4:20-26.

43. Gatzka, C.D., Schobel, H.P., Klingbeil, A.U., Neumayer, H.H., and Schmieder, R.E. 1995. Normalization of circadian blood pressure profiles after renal transplantation. Transplantation. 59:1270-1274.

44. Williams, D., et al. 2006. The prevalence of a raised aldosterone-renin ratio (ARR) among new referrals to a hypertension clinic. Blood Press. 15:164-168.

45. Polonia, J., Diogo, D., Caupers, P., and Damasceno, A. 2003. Influence of two doses of irbesartan on non-dipper circadian blood pressure rhythm in salt-sensitive black hypertensives under high salt diet. J. Cardiovasc. Pharmacol. 42:98-104.

46. Uzu, T., et al. 1998. Changes in the circadian rhythm of blood pressure in primary aldosteronism in response to dietary sodium restriction and adrenalectomy. J. Hypertens. 16:1745-1748.

47. Takakuwa, H., et al. 2002. Dietary sodium restriction restores nocturnal reduction of blood pressure in patients with primary aldosteronism. Hypertens. Res. 25:737-742.

48. Martino, T.A., et al. 2008. Circadian rhythm disorganization produces profound cardiovascular and renal disease in hamsters. Am. J. Physiol. Regul. Integr. Comp. Physiol. 294:R1675-R1683.

49. Livak, K.J., and Schmittgen, T.D. 2001. Analysis of relative gene expression data using real-time quantitative PCR and the 2(-Delta Delta C(T)) Method. Methods. 25:402-408.

50. Chen, H., and Kilberg, M.S. 2006. Alignment of the transcription start site coincides with increased transcriptional activity from the human asparagine synthetase gene following amino acid deprivation of HepG2 cells. J. Nutr. 136:2463-2467. 